\title{
Calcium Silicates synthesised from industrial residues with the ability for $\mathrm{CO}_{2}$ sequestration
}

Manuscript ID: WMR-13-0820

Victor Morales-Flórez ${ }^{1,2}$, Alberto Santos ${ }^{3}$, Antonio López ${ }^{4}$, Isabel Moriña ${ }^{4}$, Luis Esquivias ${ }^{1,2}$

1.- Departamento de Física de la Materia Condensada, Universidad de Sevilla, 41012, Seville, Spain.

2.- Instituto de Ciencia de Materiales de Sevilla (CSIC-US), Av. Américo Vespucio 49, 41092, Seville, Spain.

3.- Departamento de Ciencias de la Tierra, Universidad de Cádiz, 11510, Puerto Real, Spain.

4.- Instalaciones INABENSA SA, CIL Torrecuéllar, Seville, Spain.

* Corresponding author:

Víctor Morales-Flórez

Departamento de Física de la Materia Condensada, Facultad de Física, Av. Reina Mercedes a/n, Universidad de Sevilla, E-41012, Seville, Spain. Email: vmorales@us.es

\section{Abstract}

This work explored several synthesis routes to obtain calcium silicates from different calcium-rich and silicarich industrial residues. Larnite, wollastonite and calcium silicate chloride were successfully synthesised with moderate heat treatments below standard temperatures. These procedures help to not only conserve natural resources, but also to reduce the energy requirements and $\mathrm{CO}_{2}$ emissions. In addition, these silicates 
have been successfully tested as carbon dioxide sequesters, to enhance the viability of $\mathrm{CO}_{2}$ mineral sequestration technologies using calcium-rich industrial by-products as sequestration agents. Two different carbon sequestration experiments were performed under ambient conditions. Static experiments revealed carbonation efficiencies close to $100 \%$ and real-time resolved experiments characterised the dynamic behaviour and ability of these samples to reduce the $\mathrm{CO}_{2}$ concentration within a mixture of gases. The $\mathrm{CO}_{2}$ concentration was reduced up to $70 \%$, with a carbon fixation dynamic ratio of $3.2 \mathrm{mg} \mathrm{CO}_{2}$ per $\mathrm{g}$ of sequestration agent and minute. Our results confirm the suitability of the proposed synthesis routes to synthesise different calcium silicates recycling industrial residues, being therefore energetically more efficient and environmentally friendly procedures for the cement industry.

\section{Key words}

Industrial residues; Calcium silicate; Sustainable industry; Recycling; $\mathrm{CO}_{2}$ sequestration; $\mathrm{CCS}$ kinetics

\section{Introduction}

The $\mathrm{CO}_{2}$ concentration in the atmosphere is steadily increasing due to the growing use of fossil fuel energy as a consequence of, amongst other factors, technological and industrial developments and population growth. At the same time, there is also an increasing necessity for the control of the emissions of $\mathrm{CO}_{2}$ and other Green House Gases (GHG) with the aim of stabilising their concentration in the atmosphere. With this goal in mind, in order to mitigate climate change, it is necessary to decouple the economic and industrial development and the emission of GHG (Renforth et al. 2009, Bahor et al. 2009). To accomplish such 
objectives, improving the production processes and energetic efficiency, reducing the gas emissions and recycling residues are required.

To address these issues, some industrial residues are being considered to drain $\mathrm{CO}_{2}$ out of the atmosphere. An approach to this matter must consider jointly, as in this work, the management of the by-products and their role as a $\mathrm{CO}_{2}$ sink (López-Delgado \& Tayibi 2012). Considering the carbon capture and storage technologies (Power et al. 2013), the reactivity of some industrial by-products with $\mathrm{CO}_{2}$ can be considered for ex situ mineral sequestration (Sipila et al. 2008). This technique allows the removal of $\mathrm{CO}_{2}$ not only coming from power plants or other localised industrial sources, but also from transport means and past $\mathrm{CO}_{2}$ emissions (Morales-Flórez et al. 2011). The greatest advantage of mineral sequestration is that the GHG is converted into innocuous, stable and environmentally benign carbonate mineral, indefinitely. Its weakest points are the low speed of the reaction and the costs of the process (Sipila et al. 2008, Huijgen et al. 2007). In this sense, the high potential of industrial alkalinity sources (Kirchofer et al. 2013) will contribute to reducing the costs as well as avoiding the ecological impacts of mineral extraction on a massive scale. Amongst the appropriate industrial by-products for the capture and sequestration of $\mathrm{CO}_{2}$, some interesting proposals are cementitius materials (Galan et al. 2010), municipal solid waste incinerator bottom ashes (Rendek et al. 2006), steel slag (Huijgen et al. 2006), paper mill waste (Pérez-López et al. 2008), oil-shale wastes (Uibu et al. 2009) and phosphogypsum wastes (Cárdenas et al., 2011).

One of the sectors where carbon mineral sequestration may be useful and widely applied is cement production, which is one of the industries with the highest levels of GHG emissions, accounting for $8 \%$ of the total world $\mathrm{CO}_{2}$ emissions (Davidovits 1994). The main challenge would be to achieve economically sustainable development and, at the same time, reduce the greenhouse gases emitted. To achieve these 
two goals simultaneously, the synthesis of calcium silicates may play an important role in the economic viability and process optimisation. Calcium silicate synthesis has been, and still is, the object of exhaustive studies (Taylor 1990, Zhang et al. 2013), since these materials are the major components in cement manufacturing, and can also be used as $\mathrm{CO}_{2}$ sequester agents (Renforth et al. 2011, Santos et al. 2009).

The usual method used for cement production is based on solid-state reactions, carried out at temperatures around $1500^{\circ} \mathrm{C}$. Also, for the synthesis of the components, dicalcium silicate, solid-state chemical reactions (Fukuda et al. 1992), sol-gel technique (Santos et al. 2009) and hydrothermal synthesis (Georgescu et al. 2000) have mainly been used. Each methodology has its own characteristics, but all share a protocol that involves reagent mixtures, milling, time and heat-treatments (about $1000^{\circ} \mathrm{C}$ ). This temperature may be lower $\left(600-1000^{\circ} \mathrm{C}\right)$ when other variables are involved, for example, textural characteristics of the starting materials (Santos et al. 2009), subsequent heat treatment after the synthesis of intermediate silicates (Rodrigues \& Monteiro 1999), or replacement of the hydrothermal process by ultrasonic treatment (Mahfouz et al. 2008). In addition to temperature, different Ca and Si sources have been studied, for example, acetate, nitrates and calcined limestone (Chrysafi et al. 2007, Singh 2006, Rodríguez-Paéz et al. 2005) as the calcium source, or industrial by-products such as rice husk (Rodrigues 2003, Romano et al. 2006) as the silica source.

The present study proposes recycling industrial by-products as $\mathrm{Ca}$ and Si sources to synthesise calcium silicates; in most of the cases, larnite was obtained. Subsequently, these synthetic silicates will also be considered $\mathrm{CO}_{2}$ sequesters. 


\section{Materials and methods}

Two different calcium sources were considered. Firstly, a portlandite-rich residue produced as a wet paste in the acetylene industry (Morales-Flórez et al. 2011) was used. This residue is a calcium-hydroxide-rich slurry in a solid:water weight ratio of 1:3. The composition of the solid phase of this slurry has been studied before and the purity of the portlandite was estimated to be $97 \%$. Secondly, we used pure calcium chloride (Fluka 295\%). Calcium chloride is a by-product of the Solvay process for the manufacture of sodium carbonate, which could eventually also be obtained as a solid waste of the chlor-alkali industry (Muñoz \& Navia 2011). Two different silica sources were also considered: rice husk ash (RH) from the rice industry (Rodrigues 2003) (Herba Ricemills, Spain) and raw silica powder (NetEase, China, $\geq 99 \%$ ). Chemical analysis of the rice husk ash yielded a silica content of $92 \mathrm{wt} . \%$, with CaO being the major impurity, with a presence of $1.5 \mathrm{wt} . \%$. The raw silica powder consisted of silica fume, a very fine powder with a measured particle size between $20 \mu \mathrm{m}$ and $106 \mu \mathrm{m}$, generated during silicon metal production (Siddique \& Khan 2011), which has historically been considered a waste product. Other industrial by-products, such as calcium-rich solutions from municipal water supplies or diatomaceous earths (kindly supplied by EMASESA-Sevilla and Heineken Spain, respectively), and reactives such as sodium silicate, Ludox or calcium nitrate, were tested without better results.

\section{Synthesis routes}

The first aim of this research was to propose routes for the synthesis of calcium silicates based on the recycling of industrial residues. The minimum energy consumption has always kept in mind the need to 
enhance the efficiency and the technological viability of the proposed routes. Thus, special attention was paid to minimise the impact of the thermal treatment as this is the most energy-consuming step. Different temperatures and times were considered, but only those with the best results are shown. The heating ramp rate was always set to $60^{\circ} \mathrm{C} / \mathrm{min}$.

Sample SiP. In this case, $1.58 \mathrm{~g}$ of silica powder was mixed manually with $3.70 \mathrm{~g}$ of dried portlandite powder in an agate mortar. The portlandite slurry was previously heated at $100^{\circ} \mathrm{C}$ to obtain the dry portlandite powder. Then, the mixture was milled in a planetary mill at $400 \mathrm{rpm}$ for $20 \mathrm{~min}$. After the milling process, the homogenised powder was submitted to a lower energy two-step heat treatment of $800^{\circ} \mathrm{C}$ for $1 \mathrm{~h}$ and $600^{\circ} \mathrm{C}$ for $1 \mathrm{~h}$.

Sample RHP. The sample was prepared using $0.98 \mathrm{~g}$ of rice husk ash as the silica source and $2.30 \mathrm{~g}$ of dried portlandite paste. Previously, the rice husk ash was milled in a planetary mill at $400 \mathrm{rpm}$ for 5 min obtaining a particle size between $106 \mu \mathrm{m}$ and $202 \mu \mathrm{m}$. Then, the precursors were mixed in an agate mortar and heattreated at $800^{\circ} \mathrm{C}$ for $1 \mathrm{~h}$ and $600^{\circ} \mathrm{C}$ for $1 \mathrm{~h}$.

Sample $\mathrm{RHCl}$. This was prepared using $0.98 \mathrm{~g}$ of rice husk ash and $3.33 \mathrm{~g}$ of $\mathrm{CaCl}_{2}$. Both precursors were mixed in an agate mortar and homogenised in the planetary mill at $400 \mathrm{rpm}$ for $5 \mathrm{~min}$. Finally, the powders were heat treated at $800^{\circ} \mathrm{C}$ for $1 \mathrm{~h}$ and $600^{\circ} \mathrm{C}$ for $1 \mathrm{~h}$.

\section{Carbonation experiments}

The second aim of this work was to test the efficiency of the synthetic calcium-rich compounds as $\mathrm{CO}_{2}$ sequestration agents. In this regard, the energy consumption during the synthesis process was a key 
parameter to be minimised, in order to reduce the carbon footprint of the complete carbon sequestration process, and to maximise the viability of this technology.

The first carbonation experimental set-up assessed the carbonation capacity and efficiency of the calcium silicates: $2 \mathrm{~g}$ of the sample was dispersed in $40 \mathrm{~mL}$ of high-purity water under magnetic stirring in a reactor. Then, a $\mathrm{CO}_{2}$ flux ( $1 \mathrm{bar}, 20 \mathrm{~cm}^{3} / \mathrm{s}$ ) was bubbled through the suspension for 15 min under room pressure and temperature. Afterwards, the sample was left to rest overnight in the $\mathrm{CO}_{2}$-rich water. The resulting solid phase was separated by centrifugation and dried in air at $80^{\circ} \mathrm{C}$, and the supernatant discarded.

The continuous $\mathrm{CO}_{2}$ mineral sequestration was performed in semi-batch experiments in $1 \mathrm{~L}$ of high-purity water with the sequestration agent: firstly, $200 \mathrm{~mL}$ of the portlandite-rich slurry was used as a reference of maximum capturing conditions. Next, experiments were performed with $17.2 \mathrm{~g}$ of sample $\mathrm{RHCl}$, a synthetic calcium silicate sequestration agent. The first sample is an industrial by-product that is easily available in large amounts, but the second one was synthesised in our laboratory. For easy comparison, in the second case, a net amount of total calcium content one order of magnitude lower than in the first case was considered. In both cases, a mixture of $\mathrm{CO}_{2}$ and air (mass-flow controllers Porter $\left.\mu \mathrm{F}\right)\left(20.8 \% \mathrm{CO}_{2}\right.$ and $79.2 \%$ air) was imposed through the reactor. The gas mixture was supplied continuously to the reactor inlet (flux: $1000 \mathrm{~cm}^{3} / \mathrm{min}, 2$ bar). The outlet of the reactor was connected to a continuous $\mathrm{CO}_{2}$ gas analyser (ABB EasyLine EL3020), where the concentration of $\mathrm{CO}_{2}$ in the outlet was monitored in real-time with a resolution of $1 \mathrm{~min}$. Experiments typically took between $20 \mathrm{~min}$ and $1 \mathrm{~h}$.

The experiments started by saturating high-purity water with $\mathrm{CO}_{2}$ prior to adding the sequestration agent. The initial saturation state was achieved when the concentration of $\mathrm{CO}_{2}$ measured in the outlet stayed 
steady, as established in the inlet gas by the mass flow controllers. Then, the sequestration agent was added to the reactor and the $\mathrm{CO}_{2}$ concentration in the outlet was monitored until the initial value was obtained again. At this point, the sequestration process was considered to be finished. Inert samples were used to check the reliability of the set-up. No stirring was considered other than the vigorous gas bubbling at the bottom of the reactor.

The experimental methods and materials explained in this section and the main goals of this work are summarised in Figure 1.

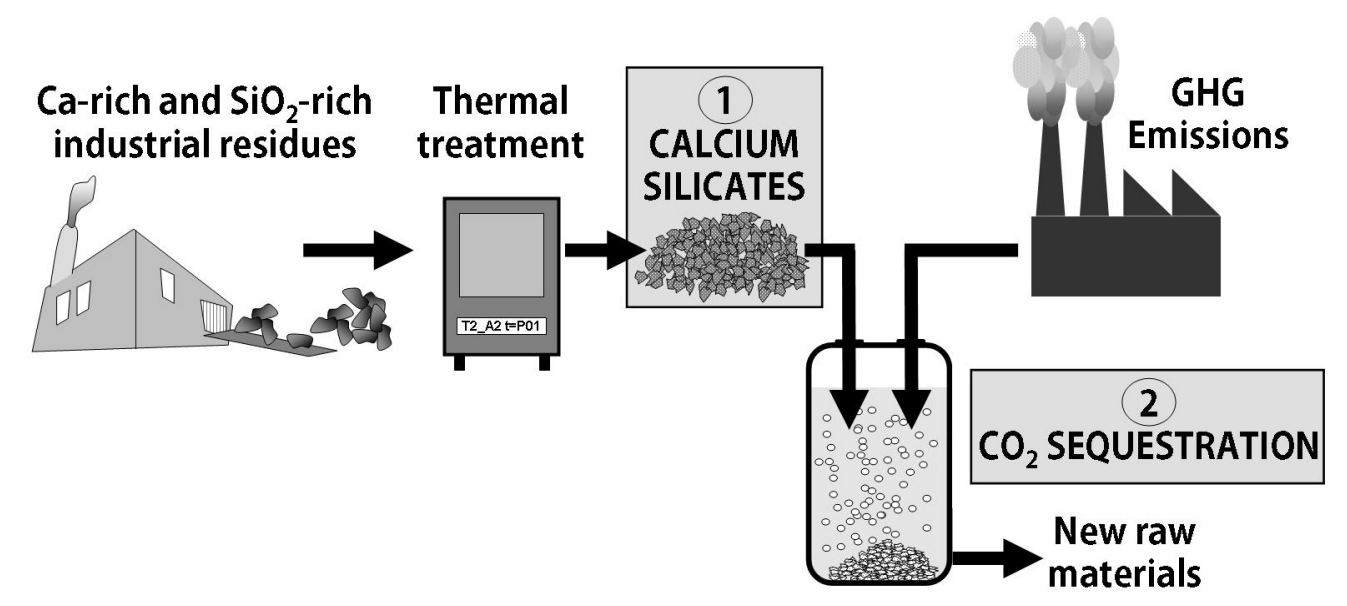

Figure 1. Experimental processes and goals of this work.

\section{Characterisation methods}

Chemical characterisation was performed by X-ray fluorescence (XRF; AXIOS Panalytical) for major elements.

The crystalline phases of the samples were identified by X-ray diffraction (XRD) in a diffractometer (Philips $X^{\prime}$ Pert) with Cu- $\mathrm{K}_{\alpha}$ radiation, from $5.00^{\circ}$ to $70.00^{\circ}$ with a step of $0.05^{\circ}$ and a counting time of $80 \mathrm{~s}$. The morphology and structure of the samples were characterised by $\mathrm{N}_{2}$ physisorption (Micromeritics ASAP2010) 
and scanning electron microscopy (SEM; SEM-FEG Hitachi S480). Physisorption experiments were performed at a constant temperature of $77.35 \mathrm{~K}$. Specific surface area and pore size distribution (PSD) were obtained by analysing the physisorption isotherm using the BET and BJH methods, respectively.

The carbonation of the samples was studied by XRD and thermogravimetric analyses (TGA; STD Q600) carried out under an $\mathrm{N}_{2}$ flux of $100.0 \mathrm{~mL} / \mathrm{min}$, starting from ambient temperature and increasing by $10^{\circ} \mathrm{C} / \mathrm{min}$ up to $1000^{\circ} \mathrm{C}$. The carbonation efficiency of the samples was estimated by comparing the weight loss observed due to the decarbonation from $450^{\circ} \mathrm{C}$ to $700^{\circ} \mathrm{C}$, and the maximum theoretical weight loss in the case of total carbonation, regarding the $\mathrm{CaO}$ content estimated by XRF.

\section{Results and discussion}

\section{Synthesis of calcium silicates}

The results of the XRF analyses are summarised in Table 1. Firstly, the obtained calcium-to-silica ratios, $\mathrm{Ca} / \mathrm{Si}$, were 1.8 for SiP, 1.7 for RHP and 1.6 for $\mathrm{RHCl}$, which were quite close to the expected values regarding the experimental synthesis procedures. In all cases, the $\mathrm{Ca} / \mathrm{Si}$ ratio values fell between unity and 2 , suggesting that mixtures of monosilicates and disilicates may have been synthesised. Major impurities of SiP and RHP samples were $\mathrm{MgO}(0.04 \% \mathrm{wt}$.$) and \mathrm{NaO}(3.18 \% \mathrm{wt}$.$) , and will be neglected from this point on.$

Regarding $\mathrm{RHCl}$ sample, the calcium-to-chlorine ratio, $\mathrm{Ca} / \mathrm{Cl}$, was 0.5 in the precursors and close to 1 in the sample. Therefore, one half of the chlorine remained in the final synthesised sample whereas the other half was expelled during heat treatment; for this reason this treatment should be performed under controlled 
conditions. Finally, there was an important loss of ignition due to dehydration of the hygroscopic and hydrated components, and the probable presence of small amounts of non-reacted precursors.

Thus, considering the XRF results, SiP would be a priori more efficient than RHP and RHCl samples, as the higher the calcium content is, the better the performance of $\mathrm{CO}_{2}$ sequestration as it allows more $\mathrm{CO}_{2}$ to be fixed for a given mass of sequestration agent.

In addition, the diffraction diagrams are plotted in Fig. 2 and the identified phases are also listed in Table 1. The resolution and sharpness of the peaks in the diffraction patterns are indicative of the crystalline degree of the sample. In this study, where moderate temperature heat treatments were used, significant background and broad peaks are present in all of the samples, indicating incomplete crystallisation. 


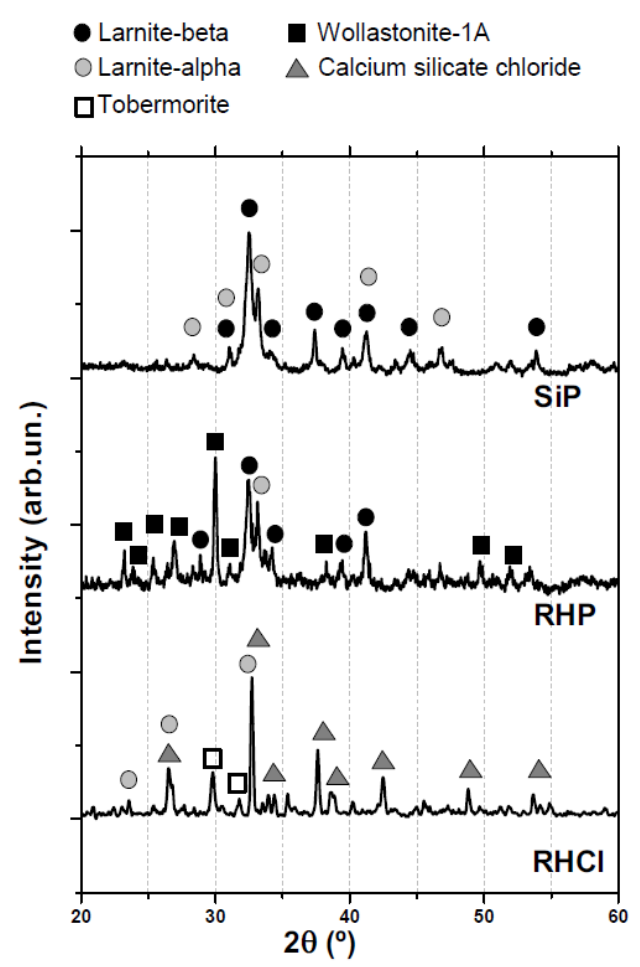

Figure 2. XRD patterns for the synthesised samples. The major identified phases are: larnite-beta, $\mathrm{Ca}_{2} \mathrm{SiO}_{4}(01-083-$ 0461); larnite-alpha (00-020-0237); wollastonite-1A, $\mathrm{CaSiO}_{3}$ (01-084-0654); calcium silicate chloride $\left(\mathrm{Ca}_{2} \mathrm{SiO}_{3} \mathrm{Cl}_{2}\right)(00$ 043-0086); and tobermorite (C-S-H) (01-089-6458).

For the three different synthesis routes, the presence of different calcium silicates can be confirmed. The SiP sample shows an exclusive dicalcium silicate composition ( $\alpha$ - and $\beta$-larnite), as expected by the measured calcium-to-silica ratio. Therefore, this synthesis route shows a good performance for larnite production. The analysis of RHP shows the presence of two different calcium silicates (Fig. 2): larnite, as the major 
component, and wollastonite. These results prove that these industrial residues can be considered for calcium silicate production with moderate energy consumption. In addition, environmental benefits will also involve avoiding mineral extraction on a massive scale.

Finally, the RHCl sample showed the presence of three different calcium silicates; $\alpha$-Larnite and tobermorite can be identified, but the presence of $\alpha$-calcium silicate chloride $(<40 \%)$ is the most remarkable feature. Other calcium-silico-chlorides have been reported in the literature (Pöllman 2002, Kurdowski \& Miskiewicz 1985). The common features for all of these reported synthesis procedures are the presence of the three important elements, $\mathrm{Ca}, \mathrm{Si}$ and $\mathrm{Cl}$, from three different precursors and heat treatment between $800^{\circ} \mathrm{C}$ and $900^{\circ} \mathrm{C}$. However, our $\mathrm{RHCl}$ sample stands out due to the absence of $\mathrm{CaO}$ in the starting system and the presence only of the $\mathrm{SiO}_{2}-\mathrm{CaCl}_{2}$ system. To our knowledge, the synthesis of $\alpha$-calcium silicate chloride based on the $\mathrm{SiO}_{2}-\mathrm{CaCl}_{2}$ system has not been previously reported in the literature. 


\begin{tabular}{|c|c|c|c|c|c|}
\hline \multirow{2}{*}{ Sample } & \multirow{2}{*}{$\begin{array}{l}\text { Chemical composition (XRF) } \\
\text { (wt. \%) }\end{array}$} & \multirow{2}{*}{$\begin{array}{l}\text { Microstructure } \\
\text { ( } \mathrm{N}_{2} \text {-Physisorption) }\end{array}$} & \multicolumn{2}{|c|}{ Identified phases (XRD) } & \multirow{2}{*}{$\begin{array}{l}\text { Carbonation } \\
\text { efficiency } \\
\text { (TGA + XRF) }\end{array}$} \\
\hline & & & Original samples & Carbonated samples & \\
\hline SiP & $\begin{array}{l}\mathrm{CaO}=52.37 \\
\mathrm{SiO}_{2}=30.81 \\
\mathrm{MgO}=0.04 \\
\mathrm{LOI}=13.68 \\
\mathrm{Ca} / \text { Si molar ratio }=1.82\end{array}$ & $\begin{array}{l}\mathrm{S}_{\mathrm{BET}}=6.6 \mathrm{~m}^{2} / \mathrm{g} \\
\mathrm{V}_{\mathrm{p}}=26.1 \mathrm{~mm}^{3} / \mathrm{g} \\
\mathrm{R}_{\mathrm{p}}=24.7 \mathrm{~nm}\end{array}$ & Larnite & $\begin{array}{l}\text { Calcite } \\
+ \\
\text { Vaterite } \\
+ \\
\text { Larnite }\end{array}$ & $89 \%$ \\
\hline RHP & $\begin{array}{l}\mathrm{CaO}=46.99 \\
\mathrm{SiO}_{2}=29.92 \\
\mathrm{NaO}=3.18 \\
\mathrm{LOI}=16.46 \\
\mathrm{Ca} / \text { Si molar ratio }=1.68\end{array}$ & $\begin{array}{l}\mathrm{S}_{\mathrm{BET}}=10.4 \mathrm{~m}^{2} / \mathrm{g} \\
\mathrm{V}_{\mathrm{p}}=83.2 \mathrm{~mm}^{3} / \mathrm{g} \\
\mathrm{R}_{\mathrm{p}}=21.0 \mathrm{~nm}\end{array}$ & $\begin{array}{l}\text { Wollastonite } \\
+ \\
\text { Larnite }\end{array}$ & $\begin{array}{l}\text { Calcite } \\
+ \\
\text { Wollastonite }\end{array}$ & $48 \%$ \\
\hline $\mathrm{RHCl}$ & $\begin{array}{l}\mathrm{CaO}=25.95 \\
\mathrm{SiO}_{2}=17.50 \\
\mathrm{Cl}=17.23 \\
\mathrm{LOI}=37.37 \\
\mathrm{Ca} / \mathrm{Si} \text { molar ratio }=1.59 \\
\mathrm{Ca} / \mathrm{Cl} \text { molar ratio }=0.95\end{array}$ & $\begin{array}{l}\mathrm{S}_{\mathrm{BET}}=2.3 \mathrm{~m}^{2} / \mathrm{g} \\
\mathrm{V}_{\mathrm{p}}=15.1 \mathrm{~mm}^{3} / \mathrm{g} \\
\mathrm{R}_{\mathrm{p}}=23.1 \mathrm{~nm}\end{array}$ & $\begin{array}{l}\text { Larnite } \\
+ \\
\text { Calcium silicate chloride } \\
+ \\
\text { Tobermorite }\end{array}$ & $\begin{array}{l}\text { Calcite } \\
+ \\
\text { Vaterite } \\
+ \\
\text { Calcium silicate } \\
\text { chloride }\end{array}$ & $95 \%$ \\
\hline
\end{tabular}

Table 1. Summary of characterisation results. LOI: Loss of ignition. $\mathrm{S}_{\mathrm{BET}}$, specific surface area; $\mathrm{V}_{\mathrm{p}}$, specific pore volume; $\mathrm{R}_{\mathrm{p}}$, typical pore radius. Larnite, $\mathrm{Ca}_{2} \mathrm{SiO}_{4}$; wollastonite, $\mathrm{CaSiO}_{3}$; calcium silicate chloride, $\mathrm{Ca}_{2} \mathrm{SiO}_{3} \mathrm{Cl}_{2}$; tobermorite, $\mathrm{C}-\mathrm{S}-\mathrm{H}$ (calcium-silicate-hydrate); calcite and vaterite, $\mathrm{CaCO}_{3}$. Carbonation efficiencies obtained upon static carbonation experiments and estimated by TGA and XRF.

On the one hand, this chlorine content could be an important drawback for an industrial realisation of the $\mathrm{RHCl}$ synthesis process and should be controlled. On the other hand, it is well known that certain calcium chlorine contents are being considered in the cement industry and its role, advantages and disadvantages are under discussion (Taylor 1990, Bensted 2002).

Other important variables revealed throughout the synthesis process include temperature; thus, the twostep heat treatment has become an interesting strategy to save energy during silicate production. As a general rule, it was observed that an initial heat treatment at $800^{\circ} \mathrm{C}$ has to be applied in order to observe a 
calcium silicate phase (by a roughly defined diffraction pattern). Other heat treatments with lower energy consumption, below $800^{\circ} \mathrm{C}$ or suppressing the second step at $600^{\circ} \mathrm{C}$ were tested without success (not shown), suggesting a necessary initial activation thermal treatment at $800^{\circ} \mathrm{C}$ for $1 \mathrm{~h}$ at least, although the temperature can be subsequently lowered to $600^{\circ} \mathrm{C}$ for $1 \mathrm{~h}$ to finish the minimum silicate synthesis processes.

The experiments of $\mathrm{N}_{2}$ physisorption have resolved several features of the submicrometric structure of the samples (Table 1). The three samples present quite similar values of specific surface area, ranging from 2.3 $\mathrm{m}^{2} / \mathrm{g}$ to $10.4 \mathrm{~m}^{2} / \mathrm{g}$, and similar typical pore radii, of c.a. $23 \mathrm{~nm}$, have been reported, which also suggest a small typical particle size. This significant submicrostructure will enhance the reactivity of the samples for different technological applications such as carbon mineral sequestration (Gupta \& Fan 2002).

In particular, SiP and RHP samples presented the highest values of the specific surface areas, where a portlandite-rich precursor (nanometric needles $15 \mathrm{~nm} \times 200 \mathrm{~nm}, \mathrm{~S}_{\mathrm{BET}}=47.5 \mathrm{~m}^{2} / \mathrm{g}$ after ref. 3) was used, whereas in the $\mathrm{RHCl}$ sample, the structure values were significantly reduced. On the other hand, the rice husk ash presented a high specific surface area of $91.15 \mathrm{~m}^{2} / \mathrm{g}$, which was higher than others that have been previously reported (Rodrigues \& Monteiro 1999, Pimraksa 2010), enabling the RHP sample to present the highest values of specific surface area. In addition, lower milling times were needed for samples synthesised from calcined rice husk, probably because of the higher specific surface area. Finally, the high pore volume of RHP of $83.2 \mathrm{~mm}^{3} / \mathrm{g}$ indicates a broad morphology and spatial distribution of the calcium silicate crystals. Scanning electron microscopy complements the description of the morphology of the samples (Fig. 3). In all cases, a granulated phase appeared, corresponding with the previously reported sub-spherical grains of 
larnite (Chrysafi et al. 2007), which is especially relevant in SiP (identified by XRD results). The structural submicrometric features can be easily seen in all samples, with the typical particle size of RHP being smaller than that of others and their spatial arrangement broader, in accordance with the $\mathrm{N}_{2}$ physisorption results (Table 1). In this sample, additional textures can be observed, corresponding to curved nanometric sticks of $30 \times 200 \mathrm{~nm}$, similar to acicular textures already observed for wollastonite (Santos et al. 2007). Finally, calcium silicate chloride submicrometric piled sticks and prismatic or tabular morphologies were observed in $\mathrm{RHCl}$ (Pöllman 2002). 


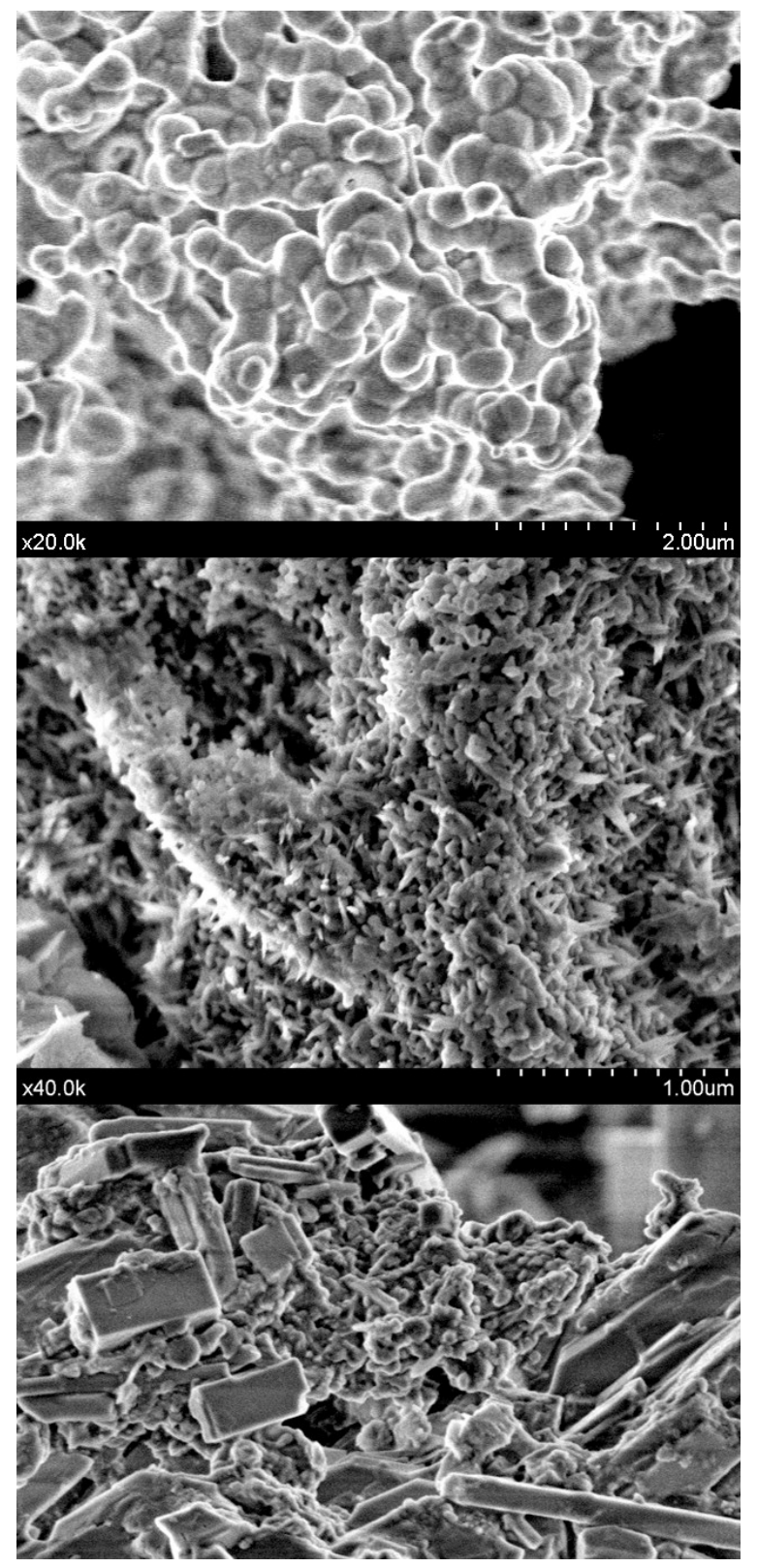

Figure 3. SEM micrographs of SiP (top), RHP (middle) and RHCl (bottom). 


\section{$\mathrm{CO}_{2}$ sequestration experiments}

The synthesised calcium silicate samples were tested as carbon sequestration agents following the carboncapture static procedure. The XRD patterns of the carbonated samples plotted in Fig. 4 reveal the precipitation of calcium carbonate in all of the samples, confirming the ability of these synthetic calcium silicates to fix $\mathrm{CO}_{2}$. In $\mathrm{SiP}^{(\mathrm{c})}$ and $\mathrm{RHCl}^{(\mathrm{c})}$ (superscript (c) stands for carbonated ones), the almost exclusive presence of calcium carbonate indicates good carbonation efficiency. Non-labelled minor peaks in Fig. 4 correspond to vaterite or residual original phases. However, well-defined peaks of the original calcium silicate are present in $\mathrm{RHP}^{(\mathrm{c})}$, indicating lower carbonation efficiency.

Similarly to previous studies (Santos et al. 2007, Santos et al. 2009), this general carbonation behaviour was confirmed by the TGA experiments. Comparative pairs of curves for as-synthesised and carbonated samples are plotted in Fig. 5 . Sample SiP(c) presented a $26 \%$ weight loss in the range $450-750^{\circ} \mathrm{C}$, corresponding to carbonation efficiencies close to $89 \%$, considering the $\mathrm{CaO}$ content of the original sample (Table 1). The estimated results of the carbon efficiency for each sample are listed in Table 1. Sample RHP(c) showed a low weight loss due to $\mathrm{CO}_{2}$ release of $13 \%$, corresponding to a carbon capture efficiency of $48 \%$. This result is in good agreement with the presence of remaining wollastonite (Fig. 4). 


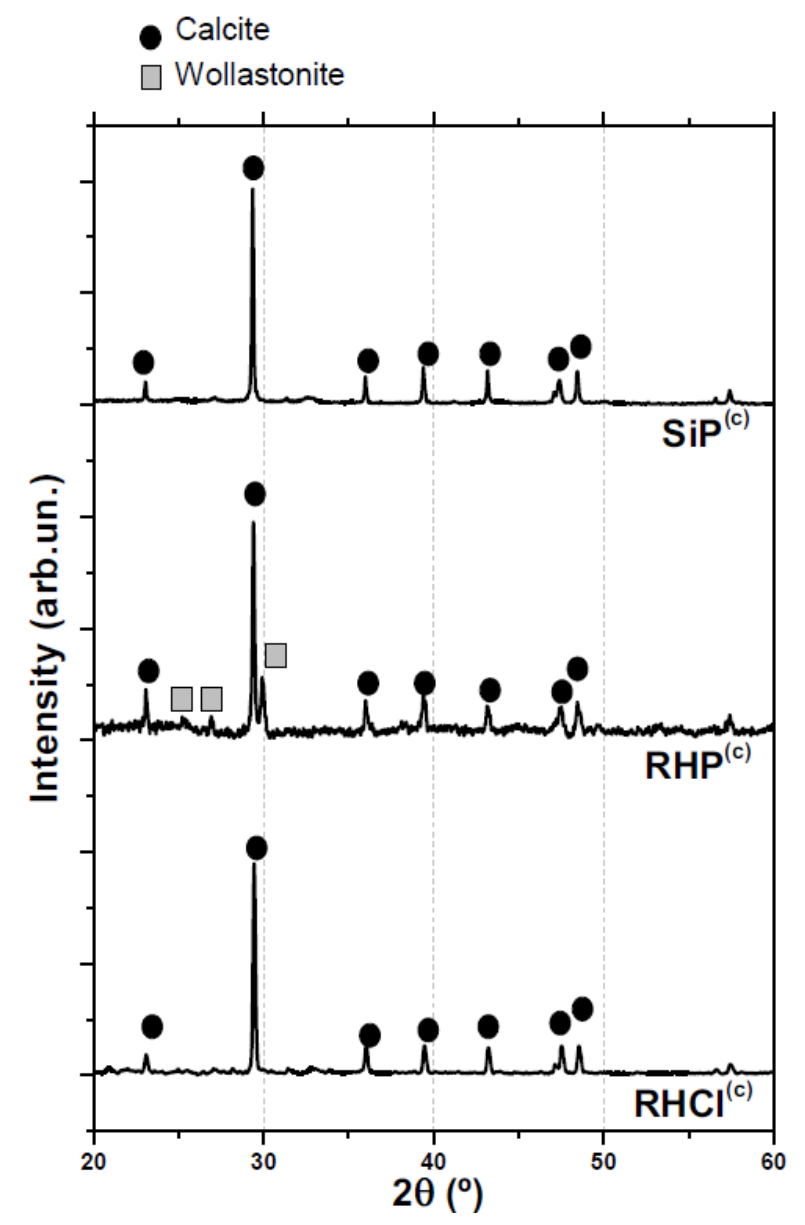

Figure 4. XRD patterns of carbonated samples. Superscript (c) stands for carbonated samples. Identified phases: calcite, $\mathrm{CaCO}_{3}$ (01-086-0174) and wollastonite, $\mathrm{CaSiO}_{3}(01-076-0186)$.

Regarding the sample $\mathrm{RHCl}^{(\mathrm{c})}$, the TGA showed a weight loss due to decarbonation of $20 \%$. This value corresponds to the highest obtained carbonation efficiency of 95\%. It is considered that the chlorine of the original phases has been transferred to the dissolution as the identified carbonated phases (calcite and 
vaterite) have no chlorine in their structure. Therefore, for the estimation of carbonation efficiency, the subtraction of the chlorine contribution in the total mass of the carbonation sample was considered. Thus, sample $\mathrm{RHCl}$ presents a reasonably good fixation power of $25 \%$ (similar to sample SiP), estimated as the ratio between the $\mathrm{CO}_{2}$ captured per gram of sequestration agent, especially if compared with other wastes which have been proposed as $\mathrm{CO}_{2}$ sequestration agents, such as steel slag (10-21\%), municipal solid waste bottomash $(2.3 \%)$, carbon fly ash $(2.6 \%)$ or even paper mill waste $(21.8 \%)$.

In summary, the synthesised sample $\mathrm{RHCl}$, mainly larnite and calcium silicate chloride, turns out to be an efficient carbon sequestration agent. Moreover, it is worth noting that $\mathrm{RHCl}$ has been synthesised considering that neither rice husk ash nor $\mathrm{CaCl}_{2}$ can be considered $\mathrm{CO}_{2}$ sinks. For this reason, $\mathrm{RHCl}$ was selected for the subsequent experiments of real-time $\mathrm{CO}_{2}$ carbonation.

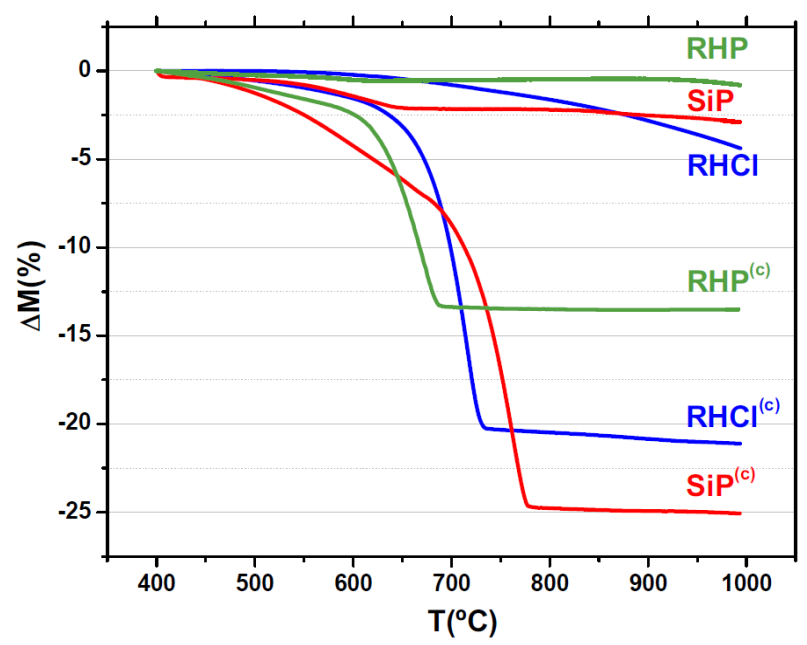

Figure 5. TGA analyses of original and carbonated samples. Superscript (c) stands for carbonated samples. 
Real-time resolved sequestration experiments. The first experiment was performed with $200 \mathrm{~mL}$ of the portlandite-rich slurry as the sequestration agent $\left(0.8 \mathrm{~mol} \mathrm{CaO}\right.$ in the reactor). Real-time data of $\mathrm{CO}_{2}$ concentration in the outlet versus time are plotted in Fig. 6. A relatively long sequestration period was observed, since $\mathrm{CO}_{2}$ concentration was diminished due to sequestration for more than $45 \mathrm{~min}$. This experiment was carried out without any mechanical or magnetic stirring, apart from the simple vigorous bubbling, as a simulation of a simple industrial embodiment. The minimum $\mathrm{CO}_{2}$ concentration in the outlet was $5.9 \%$ after 20 min of reaction (a reduction higher than $70 \%$ ). The total amount of captured $\mathrm{CO}_{2}$ was $16 \mathrm{~g}$, thus only $20 \%$ of the total capture power was used. Nevertheless, in this extremely simple experiment, 0.28 $\mathrm{g}$ of sequestered $\mathrm{CO}_{2}$ per $\mathrm{g}$ of portlandite $\left(0.07 \mathrm{~g}\right.$ of sequestered $\mathrm{CO}_{2}$ per $\mathrm{g}$ of sequestration agent) was obtained. Finally, considering the experiment duration, $1.5 \mathrm{mg}$ of $\mathrm{CO}_{2}$ was captured per $\mathrm{g}$ of sequestration agent and minute. All of these data are summarised in Table 2.

\begin{tabular}{lll}
\hline Sequester agent & $232 \mathrm{~g}$ portlandite slurry & $17.2 \mathrm{~g} \mathrm{RHCl}$ \\
\hline Active agent & $0.8 \mathrm{~mol} \mathrm{CaO}$ & $0.08 \mathrm{~mol} \mathrm{CaO}$ \\
Total sequestered $\mathrm{CO}_{2}$ & $16 \mathrm{~g}$ & $1.12 \mathrm{~g}$ \\
Total sequestration time & $45 \mathrm{~min}$ & $20 \mathrm{~min}$ \\
Maximum reduction of the $\mathrm{CO}_{2}$ emissions & $70 \%$ at $20 \mathrm{~min}$ & $33 \%$ at $8 \mathrm{~min}$ \\
Efficiency (used carbonation power) & $20 \%$ & $14 \%$ \\
Sequestered $\mathrm{CO}_{2} /$ sequester mass ratio & $0.07 \mathrm{~g} \mathrm{CO}_{2} / \mathrm{g}$ slurry & $0.07 \mathrm{~g} \mathrm{CO} / \mathrm{g} \mathrm{RHCl}$ \\
Sequestered $\mathrm{CO}_{2} /$ sequester mass and time ratio & $1.5 \mathrm{mg} \mathrm{CO}_{2} / \mathrm{g}$ slurry $\cdot \mathrm{min}$ & $3.2 \mathrm{mg} \mathrm{CO} / \mathrm{g} \mathrm{RHCl} \cdot \mathrm{min}$ \\
\hline
\end{tabular}

Table 2. Summary of real-time carbonation results. Reduction of the $\mathrm{CO}_{2}$ emissions in the outlet gas mixture is calculated regarding the initial $\mathrm{CO}_{2}$ concentration (20.8\%). 
The second sample used in real-time capture experiments was $\mathrm{RHCl}$. In this experiment, an amount of net calcium content of one order of magnitude lower was considered ( $0.08 \mathrm{~mol} \mathrm{CaO}$ in the reactor). Hence, 17.2 $\mathrm{g}$ of $\mathrm{RHCl}$ was poured into $1 \mathrm{~L}$ of water, following which the mixture of $\mathrm{CO}_{2}$-air was injected. The real-time data of $\mathrm{CO}_{2}$ concentration in the outlet are also plotted in Fig. 6. In this case, the sequestration process was saturated at $20 \mathrm{~min}$, and $1.12 \mathrm{~g}$ of $\mathrm{CO}_{2}$ was captured, corresponding to $15 \%$ of the total carbonation capture power.

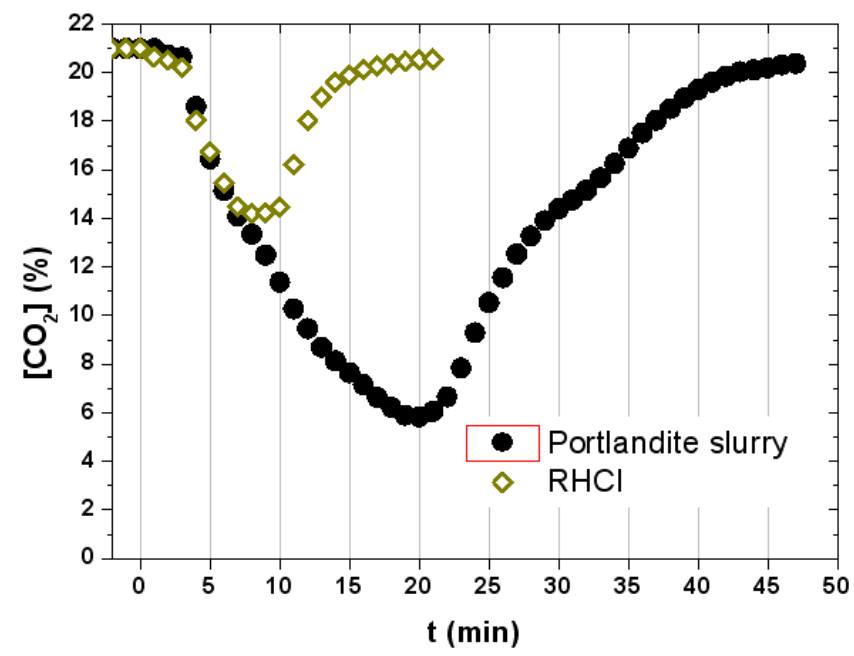

Figure 6. $\mathrm{CO}_{2}$ concentration during sequestration experiments for portlandite-rich slurry and synthetic calcium silicate $\mathrm{RHCl}$.

The minimum achieved concentration of $\mathrm{CO}_{2}$ was $14 \%$ at $8 \mathrm{~min}$, which was a reduction of $33 \%$ of the $\mathrm{CO}_{2}$ concentration in the outlet. Normalised numbers show that $0.07 \mathrm{~g}$ of $\mathrm{CO}_{2}$ was captured per $\mathrm{g}$ of sequestration agent, which was similar to the ratio reported for the portlandite-rich slurry. Finally, during 
the experiment, $3.2 \mathrm{mg}$ of $\mathrm{CO}_{2}$ was captured per $\mathrm{g}$ of sequestration agent and minute, which is a ratio that is more than two-fold that obtained for portlandite-rich slurry.

This first approach to the $\mathrm{CO}_{2}$-sequestration experiments showed a promising efficiency for the synthetic calcium silicate synthesised from two non $\mathrm{CO}_{2}$-reactive precursors, even when compared with highly reactive calcium-rich industrial by-products.

\section{Conclusions}

In this work, three different routes based on industrial by-products have been proposed for calcium silicate synthesis. Larnite, a major component of cement, wollastonite, and calcium silicate chloride $\left(\mathrm{Ca}_{2} \mathrm{SiO}_{3} \mathrm{Cl}_{2}\right.$, scarcely reported in the literature) were synthesised. These results were obtained with lower power consumption, considering the process globally. All of the proposed synthesis routes can be considered improvements for calcium silicate production and an industrial by-product recycling process. This fact must permit saving energy in related industrial sectors and the reduction of the carbon footprint of the industrial process, in addition to the benefit of using residues as precursors.

Furthermore, these silicates have been successfully tested as $\mathrm{CO}_{2}$ sequestration agents. These samples proved to be efficient even under the simplest experimental set-up for an industrial scale-up of $\mathrm{CO}_{2}$ sequestration under ambient conditions. Developing these technological improvements implies a consequent reduction of emitted gasses and sustainable and environmentally friendly industrial processes. Finally, the by-products of carbonation of the silicates are also materials with added value since they can be used as raw materials for other industrial processes, such as, for example, cement synthesis. 


\section{Acknowledgements}

This work has been supported by the project CIT-440000-09-01 of the Ministry of Science and Innovation (Spain) and by the OTRI - UCA (Spain) contract CIT-440000-09-01. We thank the technical staff of the CITIUS and the ICMS (CSIC-US) for their work. VMF would like to thank the funding program JAE-Doc from the CSIC, and the contract from IV Plan Propio US. The authors wish that these funds will not be the last ones to acknowledge to public organizations, due to the extended funds shortage that we are suffering.

\section{References}

Bahor, B., Van Brunt, M., Stovall, J., \& Blue, K. (2009) Integrated waste management as a climate change stabilization wedge. Waste Manage. Res., 27, 839-849

Bensted, J., \& Barnes, P. (2002). Structure and performance of cements. Taylor and Francis, London UK.

Cardenas-Escudero, C., Morales-Flórez, V., Perez-Lopez, R., Santos, A., \& Esquivias, L. (2011) Procedure to use phosphogypsum industrial waste for mineral $\mathrm{CO}_{2}$ sequestration. J. Hazard. Mater., 196, 431-435

Chrysafi, R., Perraki, T., \& Kakal, G. (2007) Sol-gel preparation of 2CaO·SiO 2 . J. Eur. Ceram. Soc., 27, 17071710 
Davidovits, J. (1994) Global warming impact on the cement and aggregates industries. World Resourc. Rev., 6(2), 263-268

Fukuda, K., Maki, I., \& Adachi, K. (1992) Structure change of $\mathrm{Ca}_{2} \mathrm{SiO}_{4}$ solid solutions with Ba concentration. J. Am. Ceram. Soc., 75, 884-888

Galan, I., Andrade, C., Mora, P., \& Sanjuan, M.A. (2010) Sequestration of $\mathrm{CO}_{2}$ by concrete carbonation. Environ. Sci. Tecnol., 44, 3181-3186

Georgescu, M., Tipan, J., Badanoiu, A., Crisan, D., \& Dragan, I. (2000) Highly reactive dicalcium silicate synthesised by hydrothermal processing. Cement Concrete Comp., 22, 315-319

Gupta, H., \& Fan, L.S. (2002) Carbonation-calcination cycle using high reactivity calcium oxide for carbon dioxide separation from flue gas. Ind. Eng. Chem. Res., 41, 4035-4042

Huijgen, W.J.J., \& Comans, R.N.J. (2006) Carbonation of steel slag for $\mathrm{CO}_{2}$ sequestration: leaching of products and reaction mechanisms. Environ. Sci. Technol., 40, 2790-2796

Huijgen, W.J.J., Comans, R.N.J., \& Witkamp, G.J. (2007) Cost evaluation of $\mathrm{CO}_{2}$ sequestration by aqueous mineral carbonation. Energy Convers. Manage., 48, 1923-1935 
Kirchofer, A., Becker, A., Brandt, A., \& Wilcox, J. (2013) $\mathrm{CO}_{2}$ mitigation potential of mineral carbonation with industrial alkalinity sources in the United States. Environ. Sci. Tecnol., 47, 7548-7554

Kurdowski, W., \& Miskiewicz, K. (1985) Hydration of calcium chlorosilicate $\mathrm{Ca}_{3} \mathrm{SiO}_{4} \mathrm{Cl}_{2}$. Cement Concrete Res., $15,785-792$

López-Delgado, A., \& Tayibi, H. (2012) Can hazardous waste become a raw material? The case study of an aluminium residue: a review. Waste Manage. Res., 30 (5), 474-484

Mahfouz, M., Miranda, M.S., Oliveira, M.B.R., Cassiola, F., \& Rodrigues, F.A. (2008) Biogenic cements from rice hull ash doped aluminum and iron. Chemosphere, 73, 832-836

Morales-Flórez, V., Santos, A., Lemus, A., \& Esquivias, L. (2011) Artificial weathering pools of calcium-rich industrial waste for $\mathrm{CO}_{2}$ sequestration. Chem. Eng. J., 166, 132-137

Muñoz, E., \& Navia, R. (2011) Life cycle assessment of solid waste management strategies in a chlor-alkali production facility. Waste Manage. Res., 29(6), 634-643

Pérez-López, R., Montes-Hernandez, G., Nieto, J.M., Renard, F., \& Charlet, L. (2008) Carbonation of alkaline paper mill waste to reduce $\mathrm{CO}_{2}$ greenhouse gas emissions into the atmosphere. Appl. Geochem., 23, 22922300 
Pimraksa, K., Chindaprasirt, P., \& Setthaya, N. (2010) Synthesis of zeolite phases from combustion byproducts. Waste Manage. Res., 28, 1122-1132

Pöllman, H. (2002). Composition of cement phases. Structure and Performance of Cements. Taylor and Francis, London, UK.

Power, I.M., Harrison, A.L., Dipple, G.M., Wilson, S.A., Kelemen, P.B., Hitch, M., \& Southam, G. (2013) Carbon mineralization: from natural analogues to engineered systems. Reviews in Mineralogy \& Chemistry, 77, 305360

Rendek, E., Ducom, G., \& Germain, P. (2006) Carbon dioxide sequestration in municipal solid waste incinerator (MSWI) bottom ash. J. Hazard. Mater., 128, 73-79

Renforth, P., Manning, D.A.C., \& Lopez-Capel, E. (2009) Carbonate precipitation in artificial soils as a sink for atmospheric carbon dioxide. Appl. Geochem., 24, 1757-1764

Renforth, P., Washbourne, C.L., Taylder, J., \& Manning, D.A.C. (2011) Silicate production and availability for mineral carbonation. Environ. Sci. Technol., 45, 2035-2041

Rodrigues, F.A., \& Monteiro, P.J.M. (1999) Hydrothermal synthesis of cement from rice hull ash. J. Mater. Sci. Lett., 18, 1551-1552 
Rodrigues, F.A. (2003) Low-temperature synthesis of cements from rice hull ash. Cement Concrete Res., 33, 1525-1529

Rodríguez-Paéz, J.E., Ahumada, L.M., Bustamante, J.M., \& Ruiz de Murgueitio, J. (2005) Obtención de silicatos de calcio utilizando el método de precipitación controlada. Bol. Soc. Esp. Ceram. V., 44, 421-426

Romano, J.S., Rodrigues, F.A., Bernardi, L.T., Rodrigues, J.A., \& Segre, N. (2006) Calcium Silicate cements obtained from rice hull ash: comparative study. J. Mater. Sci., 41, 1775-1779

Santos, A., Toledo-Fernández, J.A., Mendoza-Serna, R., Gago-Duport, L., De la Rosa-Fox, N., Piñero, M., \& Esquivias, L. (2007) Chemically active aerogel-wollastonite composites for $\mathrm{CO}_{2}$ fixation by carbonation reactions. Ind. Eng. Chem. Res., 46, 103-107

Santos, A., Ajbary, M., Morales-Flórez, V., Kherbeche, A., Piñero, M., \& Esquivias, L. (2009) Larnite powders and larnite/silica aerogel composites as effective agents for $\mathrm{CO}_{2}$ sequestration by carbonation. J. Hazard. Mater., 168, 1397-1403

Siddique, R., \& Khan, M. I. (2011). Supplementary Cementing Materials. Springer-Verlag, Berlin, Germany Singh, N.B. (2006) Hydrothermal synthesis of $\beta$-dicalcium silicate. Prog. Cryst. Growth Charact. Mater., 52, 77-83 
Sipila, J., Teir, S., \& Zevenhoven, R. (2008) Carbon dioxide sequestration by mineral carbonation. Review update 2005-2007, Report 2008-1 Heat Engineering Laboratory, Abo Akademi University, Finland

Taylor, H.F.W. (1990). Cement Chemistry. Academic Press, London, UK

Uibu, M., Uus, M., \& Kuusik, R. (2009) $\mathrm{CO}_{2}$ mineral sequestration in oil shale wastes from Estonian power production. J. Environ. Manage., 90, 1253-1260

Zhang, T., Gao, P., Gao, P., Wei, J., \& Yu, Q. (2013) Effectiveness of novel and traditional methods to incorporate industrial wastes in cementitious materials - An overview. Resour. Conserv. Recy., 74, 134-143 